\title{
Influence of Cobalt Substitution on Hyperfine Interactions in $\left(\mathrm{Fe}_{1-x} \mathrm{Co}_{x}\right)_{76} \mathrm{Mo}_{8} \mathrm{Cu}_{1} \mathrm{~B}_{15}$ Alloys
}

\author{
T. KAŇUCH ${ }^{a, b}$, M. Miglierini ${ }^{a, c}$, A. $\operatorname{LANČOK}^{b}$, P. ŠveC ${ }^{d}$ \\ AND E. ILLEKOVÁ ${ }^{d}$ \\ ${ }^{a}$ Department of Nuclear Physics and Technology \\ Slovak University of Technology \\ Ilkovičova 3, 81219 Bratislava, Slovakia \\ ${ }^{b}$ Inst. Inorganic Chemistry AS CR, v.v.i., 25068 Rež, Czech Republic \\ ${ }^{c}$ Nanomaterials Research Centre, 77146 Olomouc, Czech Republic \\ ${ }^{d}$ Institute of Physics, Slovak Academy of Sciences \\ Dúbravská cesta 9, 84511 Bratislava, Slovakia
}

The effect of cobalt substitution on structure, magnetic behaviour, magnetic arrangement, and hyperfine interactions in $\left(\mathrm{Fe}_{1-x} \mathrm{Co}_{x}\right)_{76} \mathrm{Mo}_{8} \mathrm{Cu}_{1} \mathrm{~B}_{15}$ $(x=0,0.1,0.2,0.25,0.5)$ is studied by the Mössbauer spectrometry for both as-quenched and annealed alloys. Partial substitution of Fe by Co resulted in an enhancement of the average value of hyperfine magnetic field distributions as a function of $x$ probably due to higher magnetic moment of Co. After annealing, a two-phase nanocrystalline structure composed of amorphous matrix and bcc-FeCo nanocrystallites was observed. Mössbauer spectra were fitted with up to four six-line patterns of narrow lines assigned to different number of Co nearest neighbours inside a bcc-FeCo lattice.

PACS numbers: 61.46.--w, 75.75.+a, 76.80.+y

\section{Introduction}

Previously, we have studied the system of $\mathrm{Fe}_{76} \mathrm{Mo}_{8} \mathrm{Cu}_{1} \mathrm{~B}_{15}$ alloy from various aspects [1]. The new system extends the study from structural and magnetic points of view, as it is known that partial substitution of Fe by Co in nanocrystalline alloys may extend their soft magnetic properties to higher temperatures. In this paper we look at the effect of Co substitution on hyperfine interactions.

\section{Experimental details}

Amorphous ribbons of $\left(\mathrm{Fe}_{1-x} \mathrm{Co}_{x}\right)_{76} \mathrm{Mo}_{8} \mathrm{Cu}_{1} \mathrm{~B}_{15}(x=0,0.1,0.2,0.25,0.5)$ alloy ( $6 \mathrm{~mm}$ wide, $20 \mu \mathrm{m}$ thick) were prepared by the method of planar-flow 
casting. The heat treatment was performed upon the sample with $x=0.5$ at different temperatures up to $555^{\circ} \mathrm{C}$ for $0.5-1 \mathrm{~h}$.

Structural features were analyzed by differential scanning calorimetry (DSC) using Perkin-Elmer DSC-7 and X-ray diffraction (XRD) by HZG-4 diffractometer ( $\mathrm{Cu} K_{\alpha}$ radiation). Transmission Mössbauer spectroscopy (TMS) was performed at room temperature (RT) using a ${ }^{57} \mathrm{Co}(\mathrm{Rh})$ source.

\section{Results and discussion}

Figure 1 depicts devitrification and structural evolution of $\left(\mathrm{Fe}_{1-x} \mathrm{Co}_{x}\right)_{76}$ $\mathrm{Mo}_{8} \mathrm{Cu}_{1} \mathrm{~B}_{15}$ alloys. It shows two main stages for $x=0-0.5$. Addition of Co moves exotherm of primary crystallization to lower temperature as compared to Cofree alloy. The second exotherm is shifted to higher temperature. XRD patterns present the evolution of the crystalline phase starting at $405^{\circ} \mathrm{C}$, confirmed by the narrow peak at about $45^{\circ}$, which progressively takes on intensity. It belongs to $\alpha$-FeCo phase in bcc which is found in these kinds of alloys [2-4]. XRD of $x=0$, $0.1,0.2,0.25$ confirm full amorphicity of the as-cast alloys as shown in Fig. 1b for $x=0.5$.
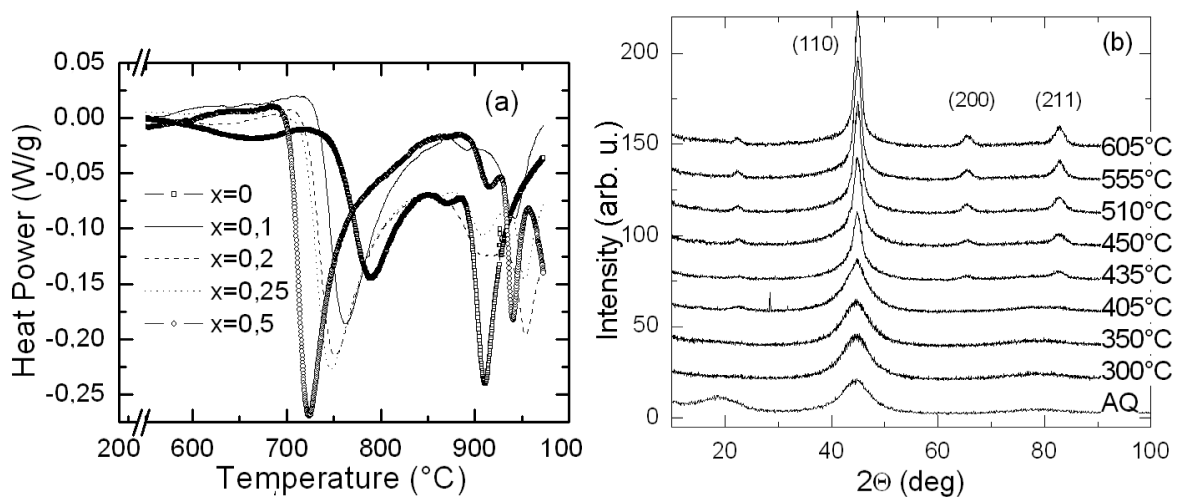

Fig. 1. DSC curves of $\left(\mathrm{Fe}_{1-x} \mathrm{Co}_{x}\right)_{76} \mathrm{Mo}_{8} \mathrm{Cu}_{1} \mathrm{~B}_{15}$ for $x=0-0.5$ (a) and X-ray diffraction patterns as a function of annealing temperature $T_{\mathrm{a}}$ for $x=0.5$ (b).

Figure 2a shows the Mössbauer spectra of the amorphous alloys from both sides of the concentration interval. The spectral shape for $x=0$ corresponds to an alloy near magnetic phase transition (the Curie temperature equals $38^{\circ} \mathrm{C}[1]$ ). On the other hand, the spectrum for $x=0.5$ shows broadened pattern reflecting a ferromagnetic state of the alloy. It can be seen that addition of Co causes accentuation of hyperfine magnetic interactions within the alloy. This is confirmed by monotonous increase in the average hyperfine magnetic field $\langle B\rangle$ with $x$ (inset in Fig. 2a). Thus, we may assume that the Curie temperature of the alloy will increase, too, as observed also for the $\left(\mathrm{Fe}_{1-x} \mathrm{Co}_{x}\right)_{79} \mathrm{Mo}_{8} \mathrm{Cu}_{1} \mathrm{~B}_{12}$ alloy [2]. 


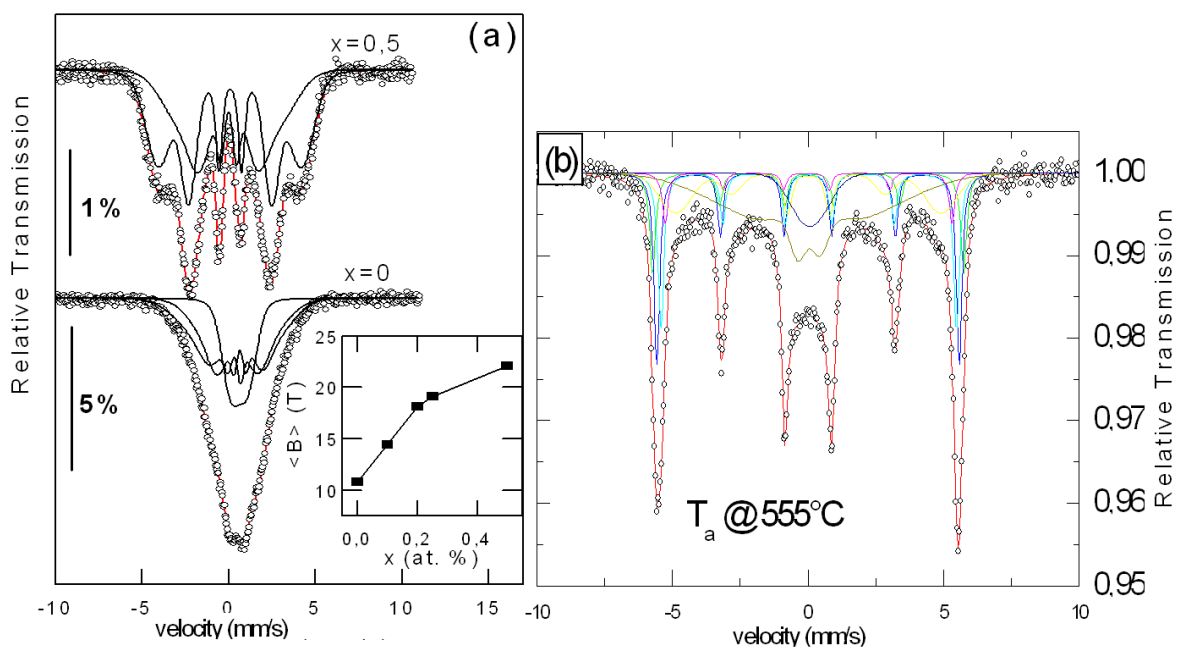

Fig. 2. Mössbauer spectra of the amorphous $\left(\mathrm{Fe}_{1-x} \mathrm{Co}_{x}\right)_{76} \mathrm{Mo}_{8} \mathrm{Cu}_{1} \mathrm{~B}_{15}$ (a) and $\left(\mathrm{Fe}_{0.5} \mathrm{Co}_{0.5}\right)_{76} \mathrm{Mo}_{8} \mathrm{Cu}_{1} \mathrm{~B}_{15}$ annealed at $555^{\circ} \mathrm{C}(\mathrm{b})$. The inset in (a) shows average hyperfine fields $\langle B\rangle$ in the as-cast alloys as a function of the Co contents $x$.

Heat treatment of the alloys causes gradual devitrification after which this complex system consists of (nano)crystallites embedded in an amorphous residual matrix. Representative spectrum of the sample annealed at $555^{\circ} \mathrm{C}$ (well beyond the first stage of crystallization) is shown in Fig. 2b. It consists of well resolved sharp lines representing the crystalline phase and broadened pattern ascribed to the amorphous matrix. Such spectra were deconvoluted by several components. Four sextets, with the hyperfine fields of about $35.9,34.8,33.8$, and $32.5 \mathrm{~T}$ can be ascribed to $\alpha$-FeCo phase in bcc arrangement. Each of them represents different number of Co nearest neighbours of Fe. Their average value is in good agreement with the value obtained in [5] for the $\mathrm{Fe}_{39} \mathrm{Co}_{39} \mathrm{Nb}_{6} \mathrm{Cu}_{1}$ alloy but lower than that of a binary $\mathrm{Fe}_{60} \mathrm{Co}_{40}$ for an ordered phase reported in [6]. Relative contributions of the crystalline components (CR) are illustrated in Fig. 3a as a function of $T_{\mathrm{a}}$.

Amorphous matrix was modelled by two distributions of magnetic hyperfine fields and one distribution of quadrupole doublets. The high magnetic field $(B 1)$ represents the interface of the crystalline phase affected by the magnetic exchange interactions among grains and the low magnetic field (B2) represents regions depleted of $\mathrm{Fe}$ and Co. The distribution of quadrupole doublets belongs to regions depleted of $\mathrm{Fe}$ and $\mathrm{Co}$ which are paramagnetic as they consist mainly of $\mathrm{Mo}, \mathrm{Cu}$, and $\mathrm{B}$.

Figure $3 \mathrm{~b}$ depicts the dependence of hyperfine magnetic fields for amorphous and crystalline phases as a function of annealing temperature. Hyperfine magnetic fields of crystalline components do not significantly change with increasing $T_{\mathrm{a}}$ which implies practically no change in the structural arrangement. $\langle B\rangle$ increases with $T_{\mathrm{a}}$ confirming that the increased amount of the crystalline phase, 

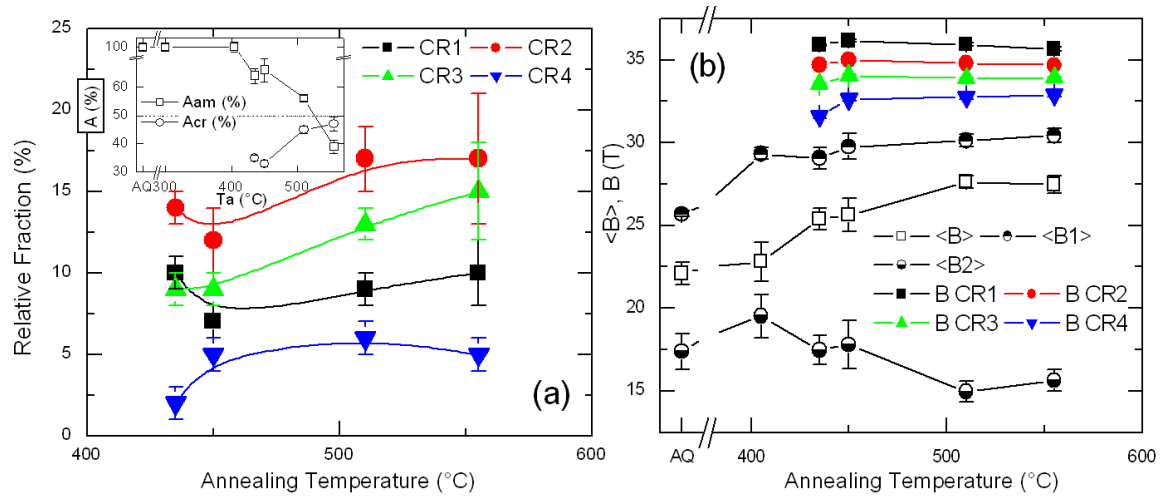

Fig. 3. Relative area of crystalline components (a) (the inset shows the overall relative areas of the crystalline and amorphous phases) and average hyperfine magnetic field $\langle B\rangle$ of the distributions and hyperfine magnetic fields $B$ of the crystalline phases (b) as a function of $T_{\mathrm{a}}$ for the $\left(\mathrm{Fe}_{0.5} \mathrm{Co}_{0.5}\right)_{76} \mathrm{Mo}_{8} \mathrm{Cu}_{1} \mathrm{~B}_{15}$.

as evidenced in Fig. 3a, influences the increase in hyperfine interactions probably due to ferromagnetic grain-to-grain coupling with consequent polarization of the amorphous matrix.

\section{Acknowledgments}

This work was supported by the grants VEGA 1/4011/07, 2/5096/25, APVT-20-008404, APVV-0413-06, MSM6198959218 and KAN 400100653.

\section{References}

[1] M. Miglierini, J. Degmova, T. Kanuch, J.-M. Greneche, Properties and Applications of Nanocrystalline Alloys from Amorphous Precursors, Kluwer Academic, 2005 , p. 421.

[2] C.F. Conde, A. Conde, D. Janickovic, P. Svec, J. Magn. Magn. Mater. 304, e739 (2006).

[3] M.E. McHenry, M.A. Willard, D.E. Laughlin, Prog. Mater. Sci. 44, 291 (1999).

[4] J.S. Blazquez, C.F. Conde, A. Conde, J.M. Greneche, J. Alloy Comp. 397, 173 (2005).

[5] J. S. Blazquez, A. Conde, J.M. Greneche, Appl. Phys. Lett. 81, 1612 (2006).

[6] B. DeMayo, D.W. Forester, S. Spooner, J. Appl. Phys. 41, 1319 (2007). 